\title{
THE INFLUENCE OF CALCIUM AND OTHER ELEMENTS ON THE FRUCTIFICATION OF THE PEANUT, IN CONNECTION WITH THE ABSORPTION CAPACITY OF ITS GYNOPHORES ${ }^{1}$ )
}

\author{
G. G. BOLHUIS and R. W. STUBBS
}

Laboratory of Tropical Agriculture, Agricultural University, Wageningen

\section{SUMMARY}

The results of the present investigation can be summarized as follows :

1 The presence of moisture in the fruiting medium proved to be essential to fructification of the peanut plant. Absence of moisture resulted in no fruit being set, irrespective of the fruiting medium used and the varieties.

2 Of the elements calcium, potassium, magnesium, sodium and ammonium, calcium was the only one that had a favourable influence on fructification, and whose presence in the fruiting medium is absolutely necessary.

3 Potassium, magnesium and ammonium exerted a harmful influence when they occurred alone in the fruiting medium. This influence resulted in the gynophores breaking down into slime and eventually dying. However, magnesium proved to be less harmful than potassium.

4 A decline in the degree of fructification took place when potassium or magnesium was present in an excess quantity as compared with calcium. On the other hand, the degree of fructification in the case of experimental treatments with a high $\mathrm{Ca} / \mathrm{K}$ or $\mathrm{Ca} / \mathrm{Mg}$ ratio was higher than in treatments with a corresponding $\mathrm{Ca} / \mathrm{H}$ ratio.

5 Sodium exerted a harmful influence on the gynophore.

6 In the course of a review of results the phenomena arising from the harmful effects of potassium and magnesium were correlated with the function of calcium as a constituent of the middle lamella of the cell wall.

\section{INTRODUCTION}

The peanut (or, as it is called in England, the groundnut), Arachis hypogaea L., is one of the few plants which possesses the property of geocarpy. The plant produces overground flowers, the ovaries of which, located in the bottom of the calyx tube, develop after fertilization into a gynophore, which then penetrates the soil by means of a hard point and develops the fruit at its end.

PetTit (1895) provided the first indirect evidence that the gynophores can take up water and nutrients, and drew attention to the presence of small hairs on the gynophore which give an acid reaction to litmus paper. BLEDSOE (1950) and other investigators also found these excrescences on the gynophores, resembling root hairs, and they were found by STOKes (1930) on the wall of the peanut shell as well. JACOBS (1947) showed that the gynophore is anatomically constructed like a stalk, and behaves like a root.

VAN DER WOLK (1914) found that water, darkness, and substances present in soil extract are essential factors in fructification. REED (1942) attaches little significance to the absorption capacity of the gynophores.

1) Received for publication 8th March, 1955. 
Burkhart and Collins (1942) obtained the first direct evidence that gynophores are capable of absorbing nutrients. In an experiment in which the zone wherein the gynophores fructificate was kept separate from that wherein the roots grow, they were able, by spectrographic methods, to demonstrate the presence, in all parts of the plant, of the lithium that had been assimilated by the gynophores.

One element, which Burkhart and Collins (1942), Brady and Colwell (1945), Mehlich and Reed (1947), and Thornton and Broadbent (1948) all consider to be of great importance to fructification, is calcium, whose presence in the fruiting zone is not merely desirable, but essential. The results of the investigations carried out by BRADY (1948) and by HARRIS (1949) prove that calcium is inadequately transported in the plant. BLEDSOE et al. (1949) confirmed this inadequate transport in an experiment with radioactive calcium. The $\mathrm{Ca}^{45}$ ions, which had been taken up by the roots, could only be found by the investigators in the young gynophores. In this connection, WIERSUM (1951) concluded that no transport of water to the developing fruit takes place via the xylem unless the fruit is brought into the open air.

According to HaRris. (1949), apart from calcium, sulphur is the only element whose presence in the fruiting zone is desirable. Burkhart and Coluins (1942) and BRADY et al. (1948) state that potassium generally exerts an unfavourable influence on fructification.

The results of the experiments with magnesium which were carried out by Sommer and Baxter (1942), Brady et al. (1948) and Bledsoe and Harris (1950) showed that this element has a favourable effect on pod filling.

The gynophores' capacity for absorbing a number of other ions, and their transport to other parts of the plant, were demonstrated by TновNтоN and BROADBENT (1948) with radioactive nitrogen, and by HARRIS (1949) with radioactive phosphorus and cobalt - in which connection, HARRIS says, the condition of nutrition of the plant plays a part in the assimilation of ions by the gynophores.

\section{Procedure}

The investigation carried out at the Laboratory of Tropical Agriculture consisted of a series of three experiments, performed in the years 1951, 1952, and 1953. Although the experiments differed from each other in plan, the technical execution was the same in each case.

The method applied here in order to keep the zone in which the gyno phores had to develop separate from that of the roots differs from the method applied by BLEDSOE et al. (1946). Instead of using whole parts of stalks, like BLEDSOE et al., who conducted stalks of the runner type over trays filled with quartz sand to a depth of 10 centimetres, in these tests one single gynophore was conducted into the specific fruiting medium. For this purpose, glass tubes with flat or round bottoms, about two centimetres in diameter and about twelve centimetres in length, were used, which had been painted dull black on the outside in order to exclude the possible influence of light. By means of a pointed piece of wood, of circular cross section and with the same diameter as the tubes, a hole was pierced in the ground under the gynophore, which had not as yet reached the soil, in which hole the filled tubes were placed.

In the experiments of 1951 and 1952, the tubes were closed at the top with 


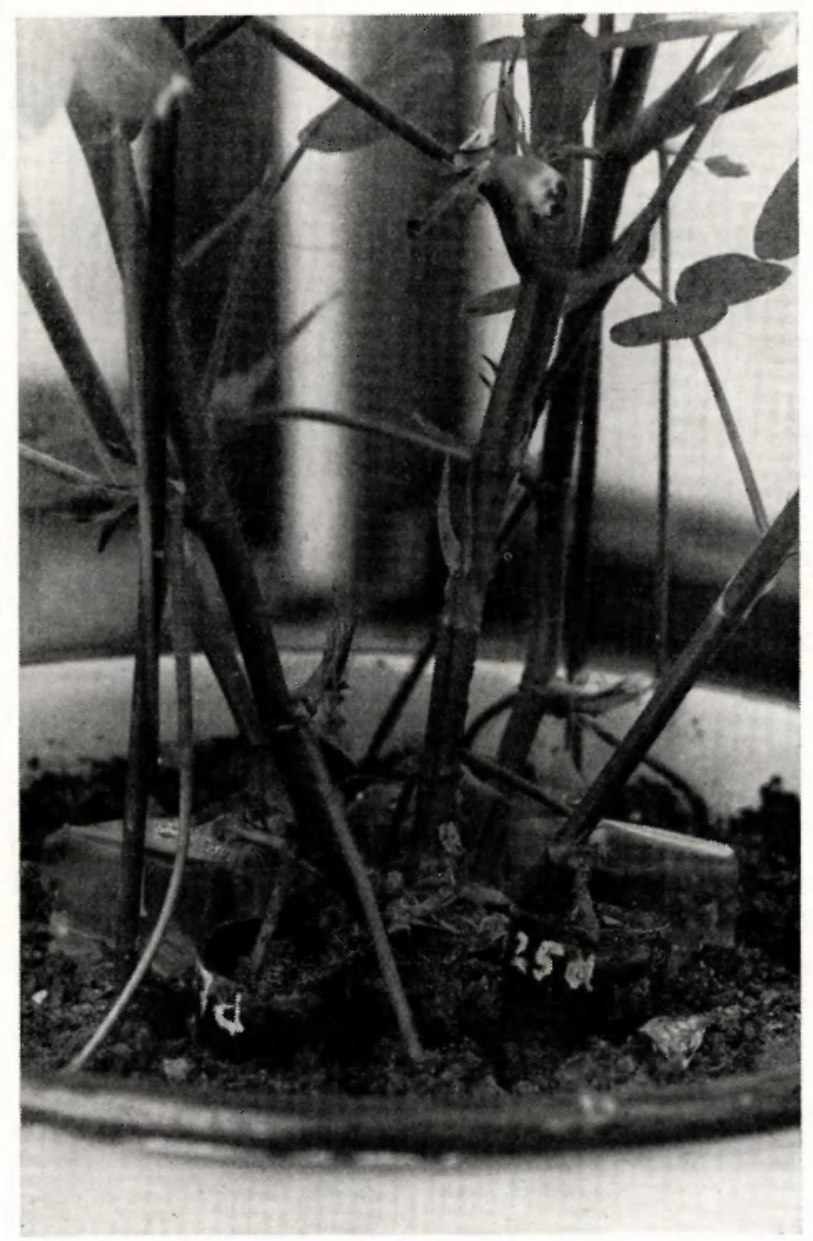

Photograph 1. Method of Conducting single gynophores in a glass tube filled With A FRUITING MEDIUM.

corks, provided with a small hole which was smeared with paraffin wax diluted with paraffin oil, to prevent the ingress of sprayed water. In the experiment of 1953, in which the plants in the pots were watered carefully with water from a beaker, the tubes were allowed to project about two centimetres above the surface of the ground, and were only covered at the top with plastic material, in order to prevent the insecticide used to control red spider from affecting the fruiting medium (Photograph 1).

When the plants were ready for harvesting, and after the gynophores treated had been cut off the plant, the tubes were drawn out of the ground and their contents carefully knocked out.

In all experiments the gynophores were judged according to their degree of fructification; in the 1951 test, also according to the extent to which they had penetrated into the tube; and in the 1953 test attention was likewise paid to changes in colour which had taken place on the gynophore or pod. 


\section{EXPERIMENT}

It has already been said in the introduction that no fruit can be set if the fruiting zone contains no moisture. In this experiment this point was studied again with reference to the behaviour of different varieties of peanut in soil, quartz sand and vermiculite. The plants taken for this purpose were divided into two main experimental groups, according to the varieties used, viz., "Schwarz 21" and "Other Varieties"; the fruiting media were divided into soil, quartz sand and vermiculite, and subdivided again into dry and wet; and all treatments were laid down in five and ten replications.

\section{EXPERIMENT ${ }^{2}$ )}

In this experiment, the object of study was the possible effect on fructification if $\mathrm{Ca}, \mathrm{K}, \mathrm{Na}, \mathrm{Mg}, \mathrm{NH}_{4}$ and $\mathrm{Mo}$ were added to the fruiting medium, either alone or in combinations of $\mathrm{Ca}$ with $\mathrm{Na}, \mathrm{K}, \mathrm{Mg}$ or $\mathrm{NH}_{4}$. For this purpose, the variety Schwarz 21 was chosen. As medium for the fruiting zone use was made of soil which acquired a content of one or two cations after special chemical treatments had been carried out on it. The soils were prepared as follows :

$\mathrm{H}$ soil : the soil was treated 18 times with $0.05 \mathrm{~N} \mathrm{HCl}$ until it was Ca-free, after which it was washed with distilled water until peptization occured. Thereafter, it was filtered until it was $\mathrm{Cl}$-free.

$\mathrm{Ca}$ soil : the soil was treated once with a solution of $0.5 \mathrm{~N} \mathrm{CaCl}_{2}$, then ten times with $0.1 \mathrm{~N} \mathrm{CaCl}_{2}$, until the $\mathrm{pH}$ was constant $(\mathrm{pH}=6.4)$. After that it was washed out with distilled water, and filtered.

$\mathrm{Ca}-\mathrm{Na}$ and $\mathrm{Ca}-\mathrm{Mg}$ soil : the soil was treated three times with a solution of $0.25 \mathrm{~N} \mathrm{CaCl} 20.25 \mathrm{~N} \mathrm{NaCl}$ (or $\mathrm{MgCl}_{2}$ ), then ten times with $0.05 \mathrm{~N} \mathrm{CaCl}_{2}$ $0.05 \mathrm{~N} \mathrm{NaCl}$ (or $\mathrm{MgCl}_{2}$ ), until the $\mathrm{pH}$ was constant $(\mathrm{pH}=6.3$ ). After that it was washed and filtered.

$\mathrm{K}$ and $\mathrm{NH}_{4}$ soil : the soil was first treated with $0.05 \mathrm{~N} \mathrm{HCl}$ until it was $\mathrm{Ca}$-free; then it was neutralized with $\mathrm{KOH}$ or $\mathrm{NH}_{4} \mathrm{OH}$ on litmus paper. After peptization it was filtered off and washed out with alcohol until it was Cl-free.

Mo soil : a little $\mathrm{NH}_{4} \mathrm{MoO}_{4}$ was added to $\mathrm{H}$ soil.

In order likewise to ascertain the influence of $\mathrm{H}, \mathrm{K}$ and $\mathrm{NH}_{4}$ soils on fruiting when calcium was present, calcium was added in the form of $\mathrm{CaSO}_{4}$. The treatments are all shown in Table 3.

A quantitative and qualitative analysis (Table 1) was carried out on the leachates obtained by mixing $40 \mathrm{~g}$ of soil with $360 \mathrm{~g}$ of quartz sand and percolating $0.05 \mathrm{~N} \mathrm{HCl}$ through the mixture until the cation of the type of soil concerned could no longer be detected.

2) Carried out by D. Bouman and H. Groenewegen. 
Table 1. Qualitative and quantitative analysis of the fruiting medium (1952 experiment).

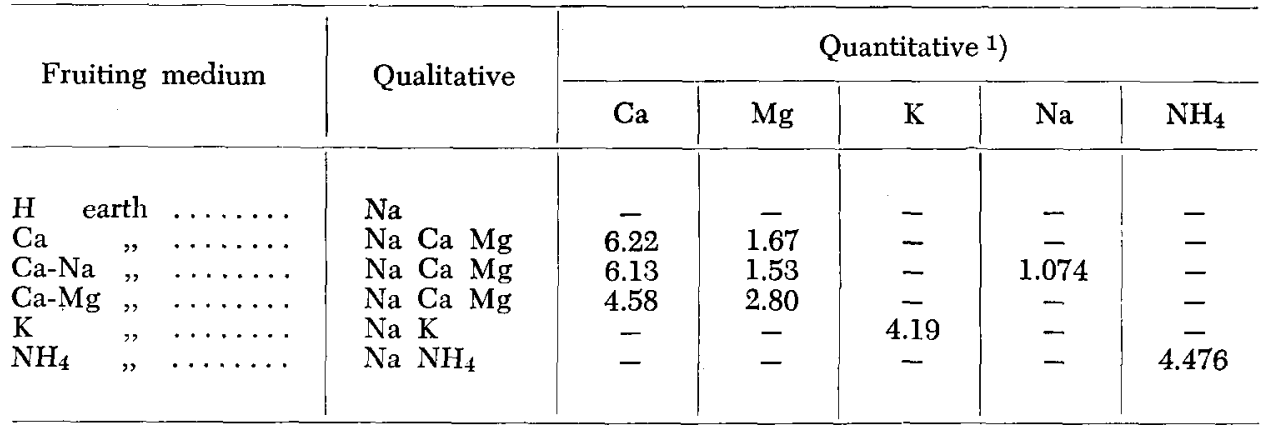

1) m.e./100 $\mathrm{g}$ of soil.

\section{EXPERIMENT}

This experiment was planned on the basis of the results of the 1952 experiment, for the purpose of investigating what effect the occurrence of $\mathrm{Ca}, \mathrm{K}$ and varying $\mathrm{pH}$ 's in the fruiting medium might have on fructification.

The variety Schwarz 21 (Spanish) was also used in this experiment. During the growing period of the plants one spoonful of $N$ P grains was administered twice (5 and 10 weeks after planting out, respectively) to the soil in which the plants were growing (a mixture of clay, leaf mould and sand), as soon as deficiency symptoms appeared on the plants.

The fruiting medium consisted of a mixture of sand and dusarit, which had previously proved its usefulness as an artificial substratum in studies of plant physiology such as those of LEIR (1953). Dusarit is a product of coal which acquires its adsorption properties by treatment with steam and sulphuric acid. At Wageningen it was found to be a substance which is not dispersible and equals humus in adsorption capacity.

By mixture with glass sand an artificial soil is obtained which is equivalent in adsorption capacity to sandy soils containing humus, or light clay soils. Any desired composition can be imparted to the dusarit complex by making separate preparations of $\mathrm{H}, \mathrm{Na}$ and $\mathrm{Mg}$ dusarit and mixing them in certain proportions. Addition of greater or lesser quantities of dusarit varies the $\mathrm{pH}$; if $\mathrm{pH}=6.5$ the dusarit will be able to adsorb about $2 \mathrm{mg}$ eq. of cations.

The fruiting medium in this experiment was prepared by mixing $\mathrm{K}, \mathrm{Mg}$. $\mathrm{Ca}$ and $\mathrm{H}$ dusarit, separately or combined in various proportions, with glasssand according to a basic ratio of $100 \mathrm{~g}$ of dusarit to $2 \mathrm{~kg}$ of sand. In this proportion, the contents of one tube were composed of approximately $2 \mathrm{~g}$ of dusarit and $40 \mathrm{~g}$ of sand. The 30 treatments (Table 4) were applied in five replications, and the 150 tubes were distributed at random among 30 plants. In the table the cation proportions are shown as proportions by weight of dusarit, the total quantity by weight of dusarit per treatment being always constant. The pH's were electrometrically determined in a $10 \mathrm{~g}$ mixture of sand and dusarit which had previously been shaken for two hours with 25 c.c. of distilled water.

The dry mixture of sand and dusarit was first saturated with distilled water and then remixed, before the tubes were filled with it.

Choice of the gynophores was restricted to those which had developed at the low internodes. During their period of development (2/2 to 3 months) the 
fruiting medium was moistened a few more times with distilled water, by means of a pipette. Evaluation of fructification took place after the plants were 135 days old.

\section{Results}

No difficulties were experienced in applying the method of causing the gynophores to develop in a zone apart from the root zone by means of glass tubes, although it was sometimes found that, if the tube was not placed directly under the gynophore, the latter, being conducted out of its perpendicular direction, was not capable of penetrating the medium, which was at times rather compact, and curled over or kinked.

The plants developed normally in all experiments, apart from a few in the 1952 experiment which rotted as a result of excessive watering, and the gynophores - the treated ones excepted - set fruit normally.

Table 2. The degree of fruit development and growth of the gynophores of "Schwarz 21" and "Other Varieties" in dry or wet soil, quartz sand and vermiculite (1951 experiment).

\begin{tabular}{|c|c|c|c|c|c|c|c|c|c|c|c|c|}
\hline \multicolumn{13}{|c|}{ Schwarz 21} \\
\hline \multicolumn{5}{|c|}{ Earth } & \multicolumn{4}{|c|}{ Quartz Sand } & \multicolumn{4}{|c|}{ Vermiculite } \\
\hline \multicolumn{3}{|c|}{ Dry } & \multicolumn{2}{|c|}{ Wet } & \multicolumn{2}{|c|}{ Dry } & \multicolumn{2}{|c|}{ Wet } & \multicolumn{2}{|c|}{ Dry } & \multicolumn{2}{|c|}{ Wet } \\
\hline$\dot{z}$ & 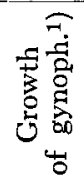 & 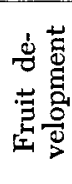 & 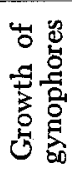 & 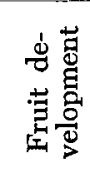 & 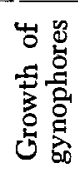 & 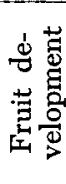 & 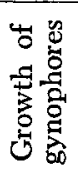 & 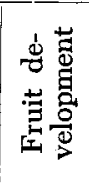 & 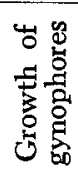 & 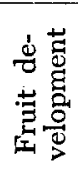 & 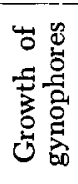 & 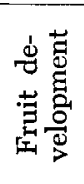 \\
\hline $\begin{array}{r}1 \\
2 \\
3 \\
4 \\
5 \\
6 \\
7 \\
8 \\
9 \\
10\end{array}$ & $\begin{array}{l}+ \\
+ \\
- \\
- \\
+ \\
+ \\
+ \\
+ \\
\text { rot }\end{array}$ & $\begin{array}{l}++ \\
- \\
= \\
+ \\
\pm \\
\pm \\
-\end{array}$ & $\begin{array}{l}+ \\
+ \\
+ \\
+ \\
+\end{array}$ & $\begin{array}{l}+++ \\
+++ \\
+++ \\
++ \\
+++\end{array}$ & $\begin{array}{l}\overline{-} \\
\overline{-} \\
\overline{-} \\
\dot{\operatorname{rot}} \\
+ \\
+\end{array}$ & $\begin{array}{l}- \\
- \\
\overline{-} \\
\dot{-} \\
\overline{+} \\
-\end{array}$ & $\begin{array}{l}+ \\
+ \\
+ \\
+ \\
+\end{array}$ & $\begin{array}{r}- \\
++ \\
+ \\
+\end{array}$ & $\begin{array}{l}\text { rot } \\
\text { rot } \\
\text { rot } \\
\overline{+}\end{array}$ & $\begin{array}{c}\dot{ } \\
\dot{ } \\
- \\
\overline{+} \\
\operatorname{rot} \\
+ \\
+ \\
+\end{array}$ & $\begin{array}{r}\dot{+} \\
+ \\
+ \\
+ \\
+ \\
+ \\
+ \\
+ \\
+\end{array}$ & $\begin{array}{l}+++ \\
+++ \\
+++ \\
+++ \\
++\end{array}$ \\
\hline
\end{tabular}

Other Varieties

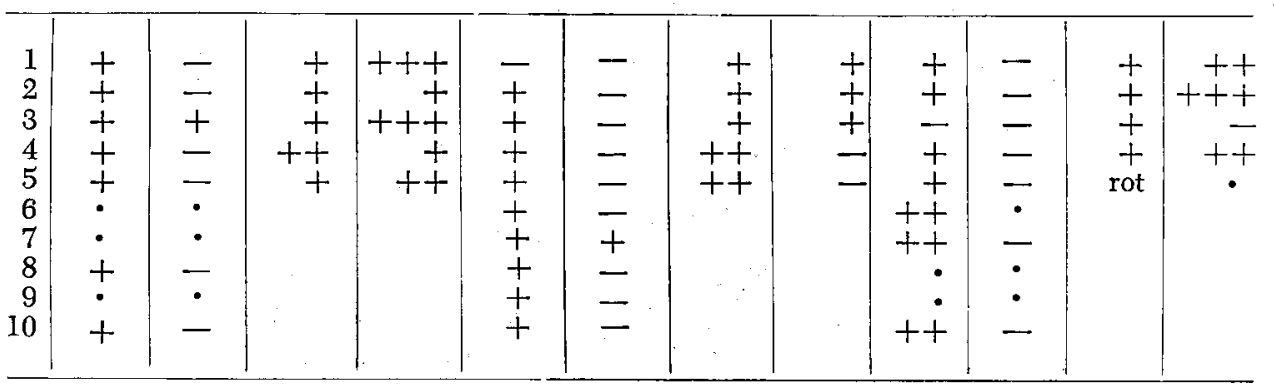

1) Degree of fruit development.

$-=$ no development.

$+=$ incipient development.

$++=$ half to full development.

$+++=$ full development. 

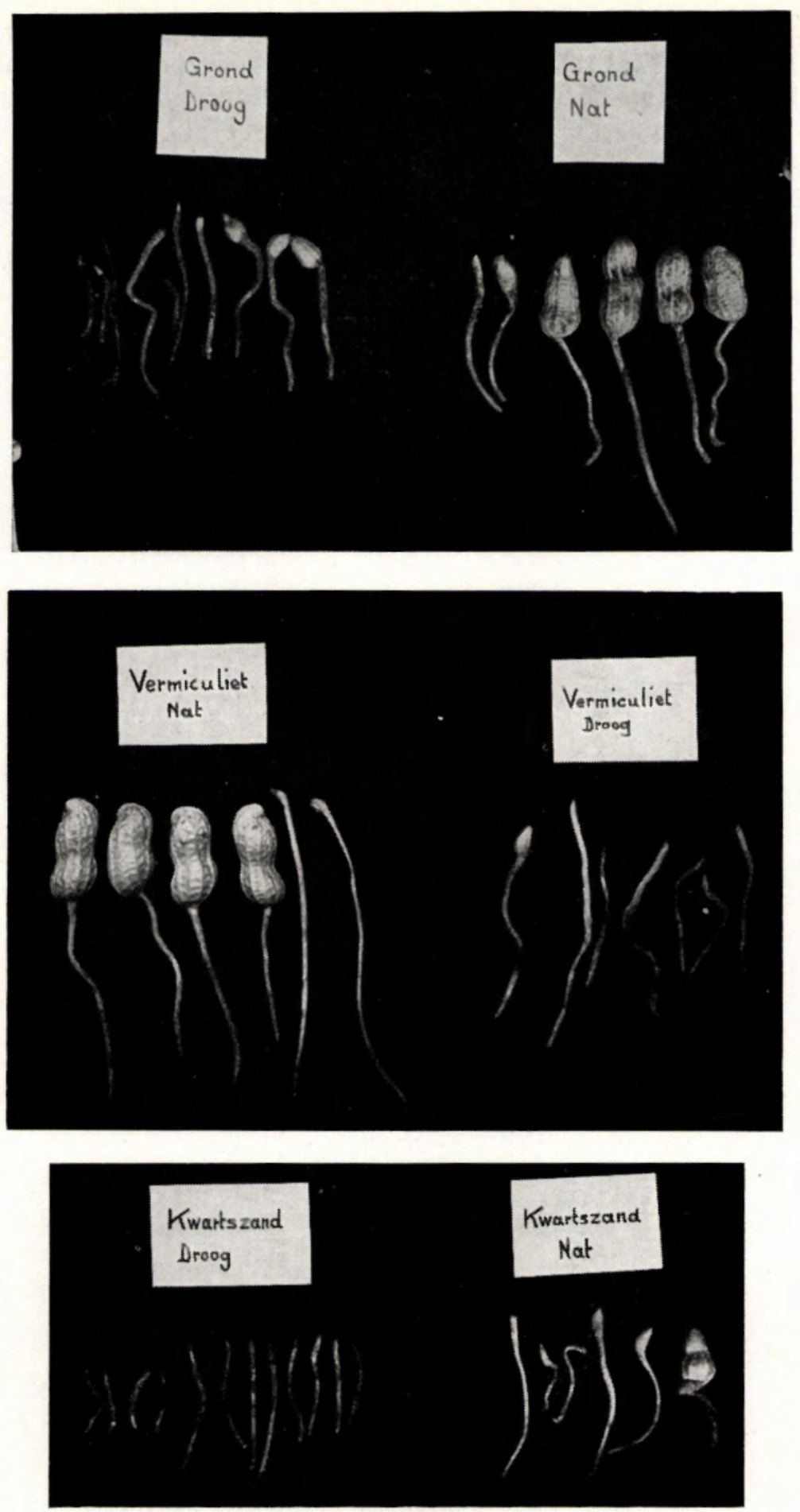

Photographs 2-4. Degree of fructification of the varieties Schwartz 21 and "other VARIETIES" IN DRY SOIL (LEFT) AND WET SOIL (RIGHT), DRY AND WET VERMICULITE, AND DRY AND WET QUARTZ SAND (RESP. LETT AND RIGHT SIDES OF THE PHOTOGRAPHS). 
Table 2 and the relevant photographs, Nos. 2, 3, and 4, show the results of the 1951 experiment, in which the influence of water and the nature of the fruiting medium on fructification was studied with reference to different varieties.

Comparison of the series of objects from the point of view of "dry" versus „wet" prompts the conclusion that water, irrespective of the nature of the fruiting medium, and irrespective of the variety concerned, is an essential factor, which has to be present in the fruiting zone to induce the gynophores to set fruit. Nevertheless, some cases of fruiting did occur in the series of "dry" objects, but these were due to the contents of the tube concerned not having remained completely dry.

No pronounced differences between varieties can be observed in the results obtained. It may, however, be said that Schwarz 21 proved to be most suitable for this test. As regards the influence of the nature of the fruiting medium on fructification, differences can definitely be perceived, viz., better development is achieved in soil and vermiculite than in quartz sand, the reason for which is to be sought in the presence of certain substances in soil and vermiculite which promote setting.

\section{The influence of calcium on fructification}

Data in Table 3, and the relevant photographs, Nos 5, 6, 7, 8, 9, 10, 11 and 12, clearly show the influence of calcium on fruit setting. This influence was manifested in the development of the gynophore into fruit when calcium was present in the objects supplied with $\mathrm{Ca}$, which development did not take place at all when calcium was absent. In this connection it must be remarked that the figures in the table have necessarily lost some of their reliability because it is not impossible that the water used during watering may have succeeded in penetrating into the tubes.

The quartz sand treatment does not give a reliable picture of the situation a result due to the sand's poor capacity for containing water, which often caused the tubes to become dry.

Nevertheless, it may be concluded that calcium has a favourable effect on fructification, and therefore has to be present in the fruiting zone.

Table 4 (Nos 2 to 5 inclusive), and the relevant photographs show the results obtained by causing the Ca-dusarit to form $1 / 2,2 / 3,9 / 10$ and $1 / 1$, respectively, of the quantity of $\mathrm{Ca}$ and $\mathbf{H}$ dusarit. This scheme resulted in an increasing degree of fructification. Here, it is not possible to ascertain what influence the differences in $\mathrm{pH}$ had. Putting on one side the case of the very acid fruiting medium ( $\mathrm{pH}=3.8)$, this increasing degree of fructification may be attributed to increasing quantities of $\mathrm{Ca}$ dusarit.

\section{The influence of potassium on fructification, alone or combined with calcium}

As can be seen from Table 3 (No. 2), Table 4 (Nos. 20 to 23, and the relevant photographs, Nos. 6 and 15, potassium exerted a very unfavourable influence, both adsorbed on soil and on dusarit; not only did fructification not take place at all, but, furthermore, the gynophores went brown to black in colour, turned to slime in the peripheral parts, and finally rotted away altogether. This effect 


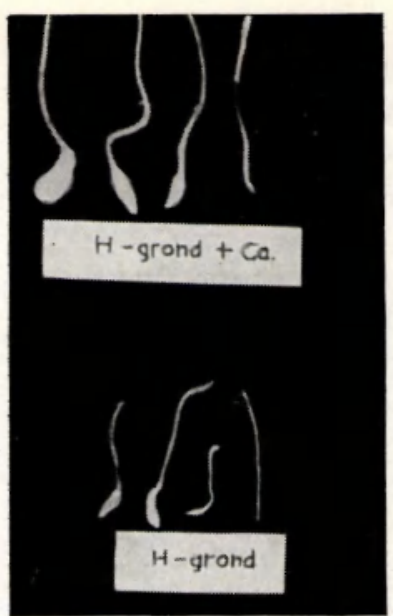

5

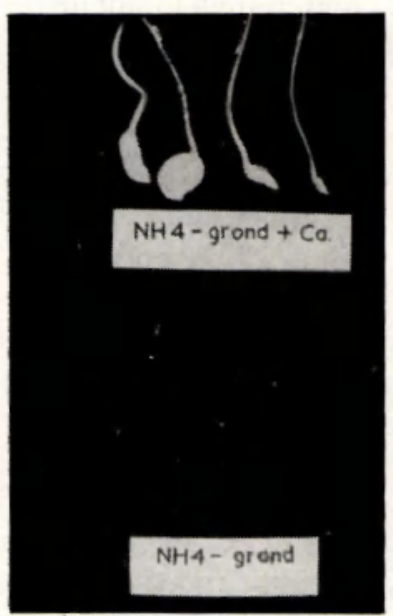

8

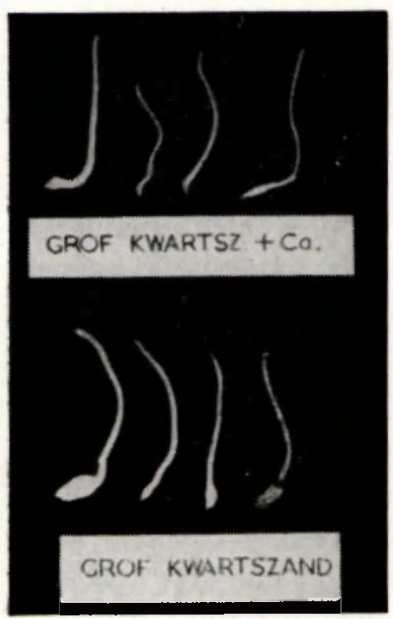

10

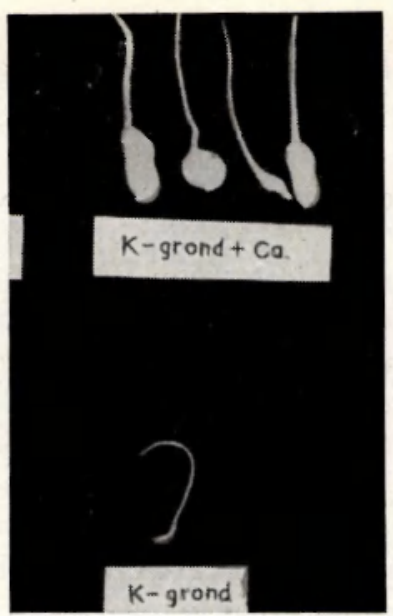

6

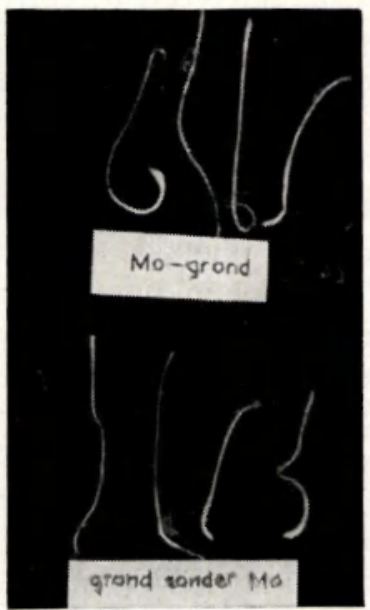

9

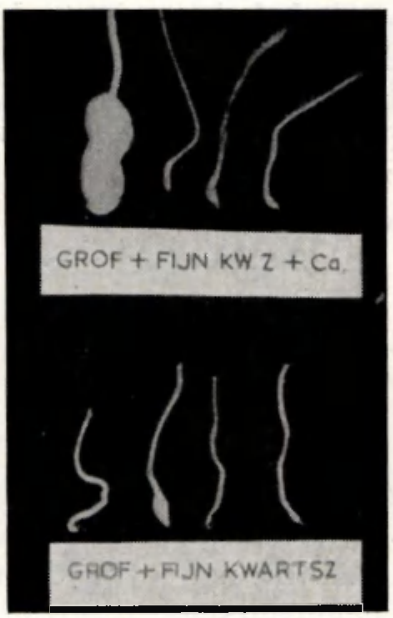

11

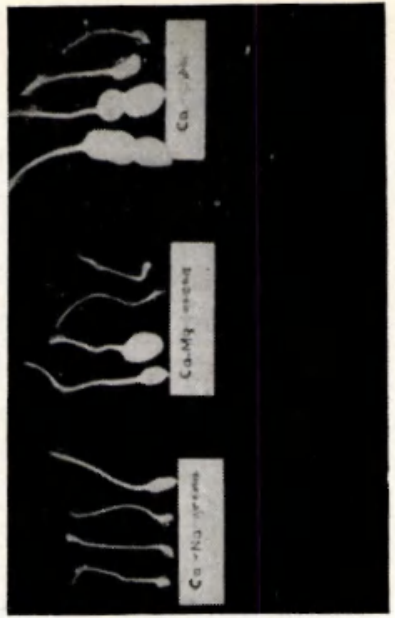

7

PhOTOGRAPHS 5-12.

DEGREE OF FRUCTIFICATION IN PREPARED SOILS AS FRUCTIFICATION MEDIA, EITHER WITH OR WITHOUT Ca.

(Experiment 1952).

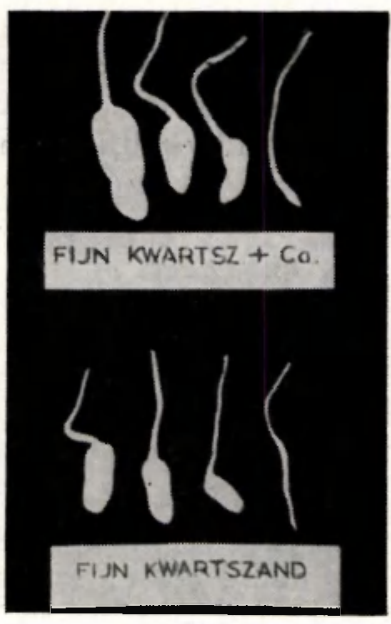

12 

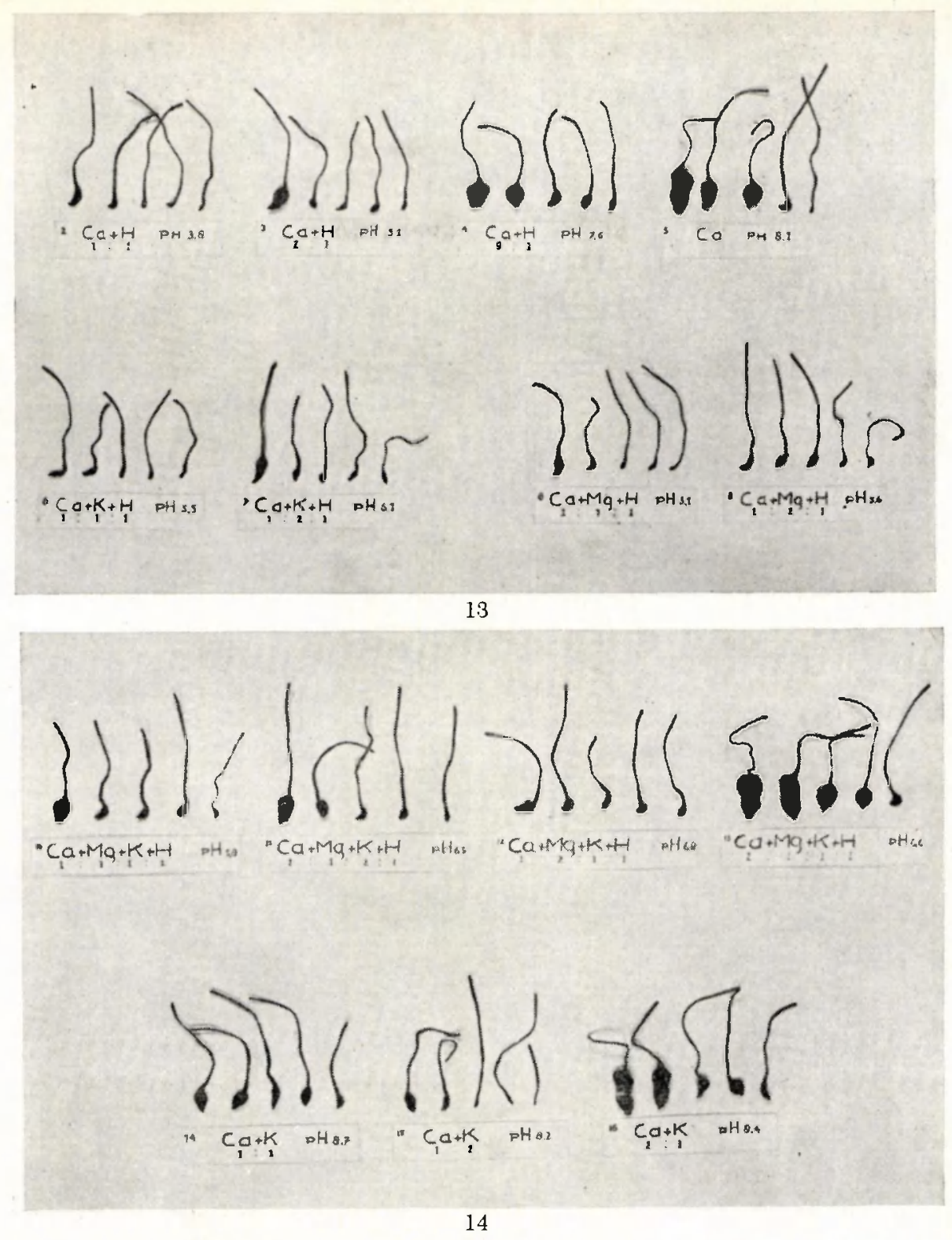

was noticeable even after the gynophores had been in contact with the potassium zone for only two days. The discoloration was not confined only to the part projecting into the fruiting medium, but extended also to the part above that an indication that the potassium had been absorbed and transported before the gynophore died.

The toxic effect of potassium was reduced or neutralized if $\mathrm{CaSO}_{4}$ or $\mathrm{Ca}$ dusarit was added to $K$ soil or $K$ dusarit, respectively (Table 3 , No. 11, and Table 4, Nos. 6, 7, 14, 15 and 16), provided the calcium absorption of the 

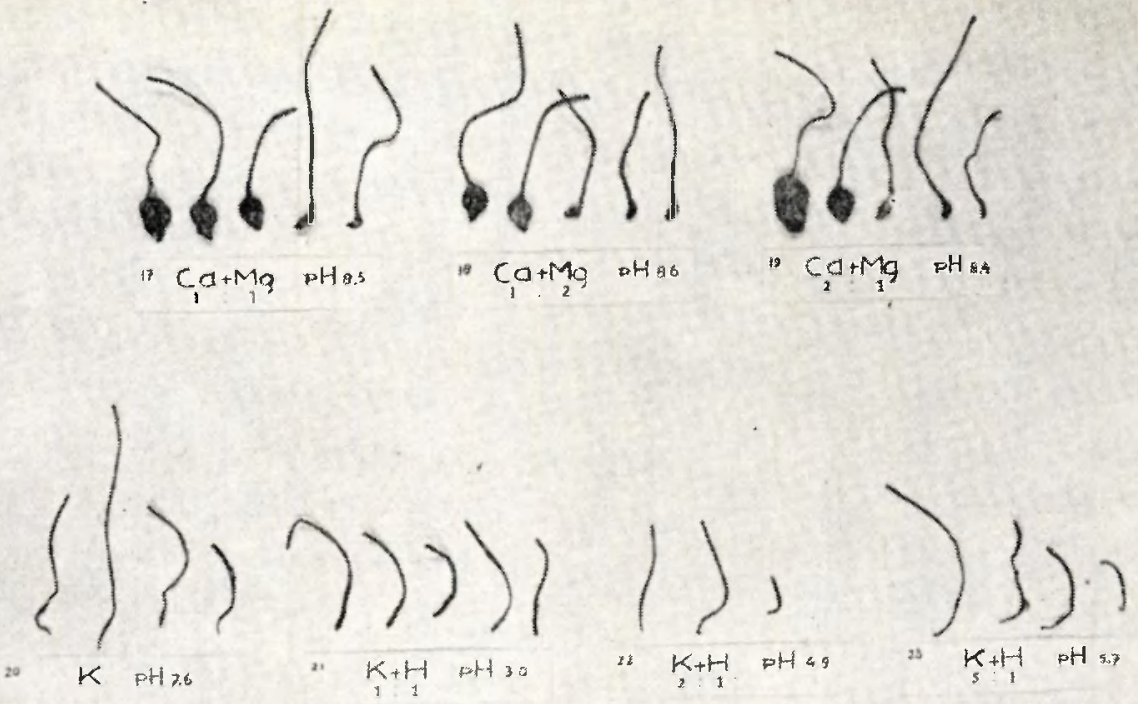

15
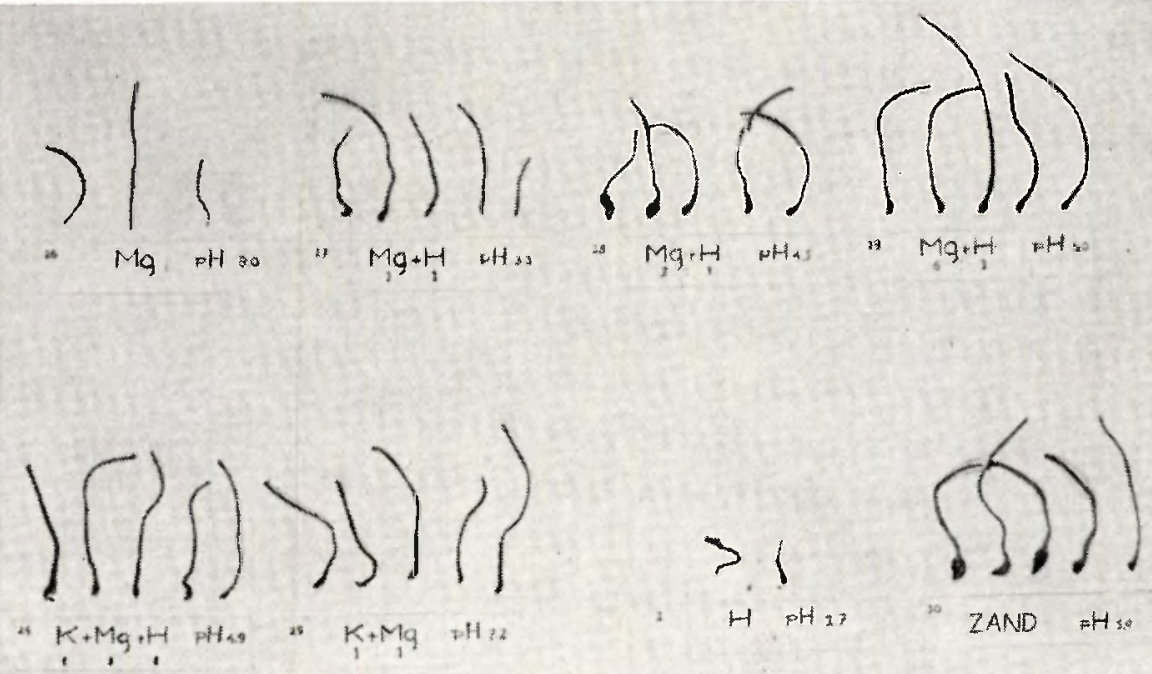

16

Photographs 13-16. Fructification in Ca-, K-, Mg-, and H-dusahit, either separate on COMBINED iN VARIOUS Ratios. (Experiment 1953).

gynophores was not repressed by the antagonism of potassium to calcium, which showed itself in the various $\mathrm{Ca}$ and $\mathrm{K}$ dusarit ratios.

Passing from a toxic to a neutral effect, potassium may even promote fructification. This conclusion has been drawn from the fact that, if the result from the $\mathrm{Ca}+\mathrm{H}$ dusarit $(2: 1)$ treatment is compared with that from $\mathrm{Ca}+\mathrm{K}$ dusarit $(2: 1)$, the potassium treatment exhibits a much greater degree of fructification, although both treatments are characterized by the same quantity of calcium. The $\mathrm{pH}^{\prime}$ 's were 5.1 and 8.4 , respectively. 
The results from the $\mathrm{Ca}+\mathrm{K}+\mathrm{H}$ dusarit treatments (Table 4, Nos 6 and 7) are characterized by a predominant influence over the unfavourable effect of potassium.

The influence of magnesium on fructification, alone or combined with calcium or potassium

Table 4 (Nos 26 to 29) and the relevant photograph No. 16 show the results achieved by causing magnesium as $\mathrm{Mg}$ dusarit to from $1 / 2,2 / 3,5 / 61 / 1$ respectively of the quantity of $\mathrm{Mg}$ and $\mathrm{H}$ dusarit. In all the treatments concerned the gynophores died and turned brown to black in colour; just as was the case with potassium, this discoloration also extended to the part of the plant projecting above the fruiting medium. A characteristic difference between these gynophores and those affected by potassium was the fact that the former did not turn to slime and died off less quickly.

Increasing quantities of $\mathrm{Mg}$ dusarit (Table 4, Nos. 26 to 29) affected the gynophores in such a way that no fruit was set when $\mathrm{Mg}$ dusarit alone formed part of the dusarit complex, and when the $\mathrm{Mg}$ - dusarit medium possessed a strongly acid character as a results of a relatively larger quantity of $\mathbf{H}$ dusarit. The other treatments produced a very slight degree of setting.

Magnesium exerted a conspicuously favourable effect when it occurred in the fruiting medium together with calcium. The degree of fructification produced by these treatments (Table 4, Nos. 17, 18, 19, Photograph 15), in which the $\mathrm{Mg}$ dusarit formed $1 / 2,2 / 3$ and $1 / 3$, respectively, of the quantity of $\mathrm{Ca}+$ $\mathrm{Mg}$ dusarit, exceeded that of the $\mathrm{Ca}+\mathrm{H}$ treatments, although a relatively greater amount of calcium was present in the latter group.

In the result from $\mathrm{Ca}-\mathrm{Mg}$ soil (Table 3, No. 14, Photograph 7), the favourable influence of magnesium as compared with the result from the Ca soil did not find expression, probably because the $\mathrm{Ca}-\mathrm{Mg}$ soil contained less calcium and more magnesium than the $\mathrm{Ca}$ soil (Table 1).

Table 3. The degree of fructification with prepared soils as fruiting media, either containing or lacking calcium.

\begin{tabular}{|c|c|c|c|c|c|c|}
\hline No. & $\begin{array}{l}\text { Fruiting } \\
\text { medium }\end{array}$ & $\begin{array}{r}\text { Minus } \\
\text { fruiting }\end{array}$ & $\begin{array}{l}\mathrm{Ca} \text { in } \\
\text { medium }\end{array}$ & No. & $\begin{array}{l}\text { Fruiting } \\
\text { medium }\end{array}$ & $\begin{array}{l}\text { Plus } \mathrm{Ca} \text { in } \\
\text { fruiting medium }\end{array}$ \\
\hline $\begin{array}{l}1 \\
2 \\
3 \\
4 \\
5 \\
6 \\
7\end{array}$ & $\begin{array}{l}\mathrm{H} \text { soil . . . } \\
\mathrm{K} \text { soil . . . } \\
\text { NH }{ }_{4} \text { soil . . } \\
\text { Mo soil . . } \\
\text { Minus Mo soil } \\
\text { Coarse quartz } \\
\text { sand ...... } \\
\text { Fine quartz } \\
\text { sand . . . . } \\
\text { Coarse/fine } \\
\text { quartz sand . }\end{array}$ & 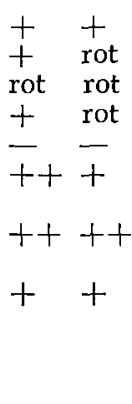 & $\begin{array}{cc}+ & \text { rot } \\
\text { rot } & \text { rot } \\
\text { rot } & \text { rot } \\
\text { rot } & \text { rot } \\
- & - \\
+ & - \\
++ & - \\
+ & -\end{array}$ & $\begin{array}{r}9 \\
10 \\
11 \\
12 \\
13 \\
14 \\
15\end{array}$ & $\begin{array}{l}\text { Ca soil } . . . \\
\mathrm{H} \text { soil }+\mathrm{Ca} \\
\mathrm{K} \text { soil }+\mathrm{Ca} \\
\mathrm{NH}_{4} \text { soil }+\mathrm{Ca} \\
\mathrm{Na}-\mathrm{Ca} \text { soil } . \\
\mathrm{Mg}-\mathrm{Ca} \text { soil . } \\
\mathrm{Coarse} \text { quartz } \\
\text { sand }+\mathrm{Ca} . \\
\text { Fine quartz } \\
\text { sand }+\mathrm{Ca} . \\
\mathrm{Coarse} / \text { fine } \\
\text { quartz sand } \\
+\mathrm{Ca} . . . .\end{array}$ & 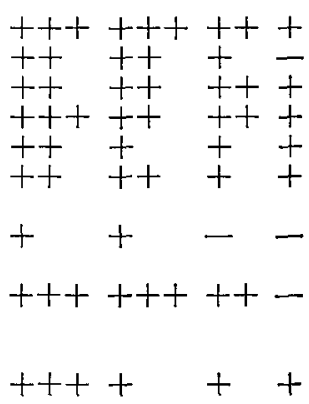 \\
\hline
\end{tabular}

Just as was the case with potassium, owing to the antagonism of $\mathrm{Mg}$ and $\mathrm{Ca}$, an increased quantity of magnesium suppressed the calcium absorption of the gynophores (Table 4, No. 18). 
In the $\mathrm{Mg}+\mathrm{K}$ dusarit treatments the gynophores developed under the prevailling influence of the unfavourable effect of potassium. Of the $\mathrm{Ca}+\mathrm{Mg}$ $+\mathrm{K}+\mathrm{H}$ series of dusarit treatments (Table 4, Nos. 10, 11, 12, Photograph 14 the treatment with the respective dusarit ratios of $2: 1: 1: 1$ produced a degree of fructification which approximated to normal. Accordingly, in this "balanced" ratio the calcium absorption of the gynophores was not suppressed.

\section{Influence of the other ions}

Table 3 (Nos. 3 and 4, Photographs 8 and 9) gives a picture of the condition of the gynophores when they developed in fruiting media of Mo and NH4 soils.

Both ammonium and molybdenum proved to have such a toxic effect on the gynophores that the latter died and completely rotted away. Addition of calcium in the form of $\mathrm{CaSO}_{4}$ to the $\mathrm{NH}_{4}$ soil neutralized the toxic effect of ammonium (Table 3, No. 12).

Sodium has a retarding effect on fructification as compared with the $\mathrm{Ca}$ soil; the $\mathrm{Ca}-\mathrm{Na}$ soil contained just as much magnesium and calcium, but a much greater quantity of sodium - a feature which found expression in a lesser degree of fructification.

Table 4. Fructification in $\mathrm{Ca}, \mathrm{K}, \mathrm{Mg}$ and $\mathrm{H}$ dusarit, alone or combined in various proportions.

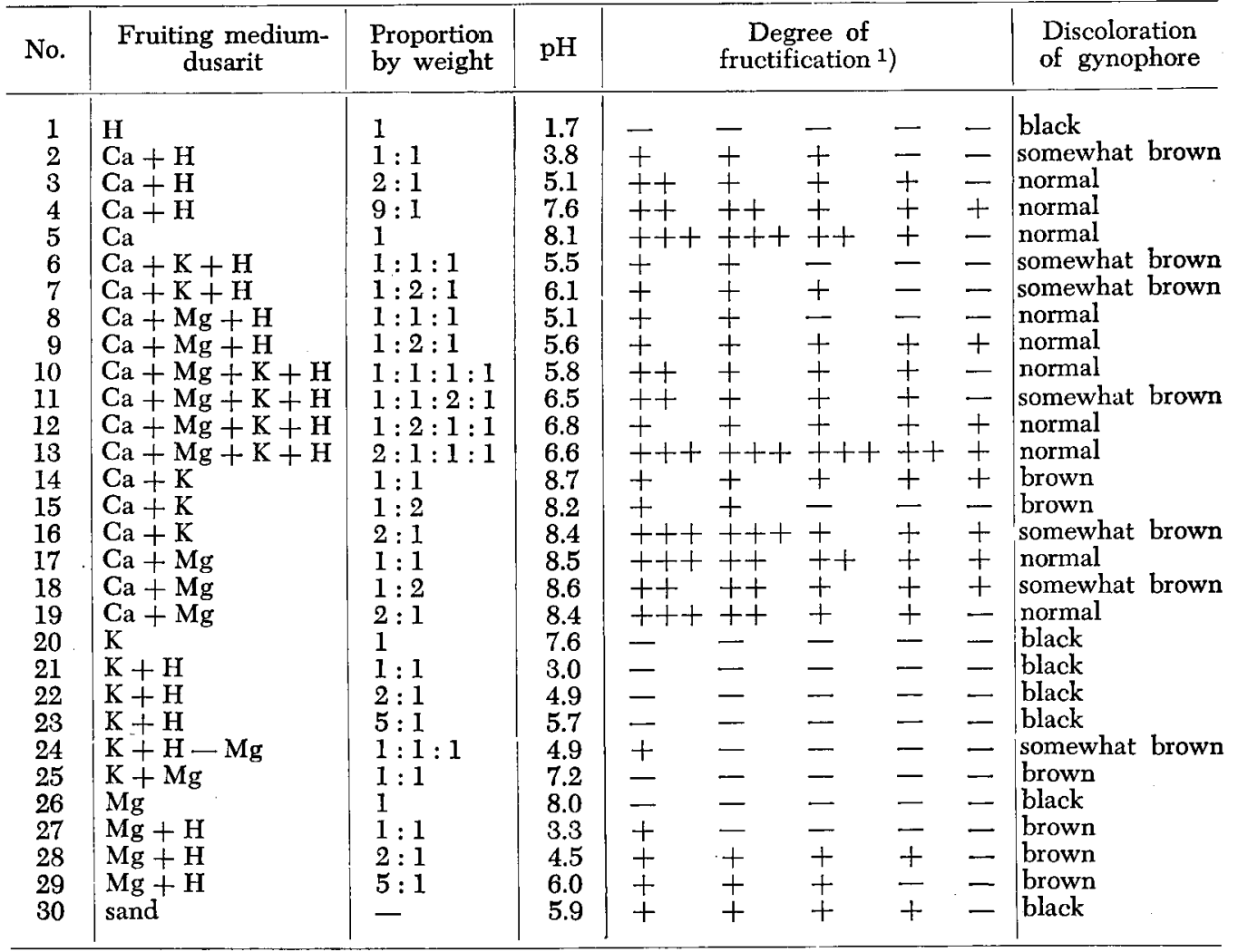

1) $-=$ no development.

$t=$ incipient development.

$++=$ half to full development.

$+++=$ full development.

In the case of the other proportions, the quantity of available calcium was at a minimum. 
The results of the investigation have proved that the peanut is a crop that, from the standpoint of nutritional physiology, consists of two systems within one plant, one of which systems (the gynophores), having arrived at a certain stage of development as regards the supply of certain nutritive elements, must be to a considerable extent independent of the other system (the roots).

In surveying the results of this investigation in connection with those of other investigators, it is nevertheless necessary to draw attention to what looks, at first sight, like an unimportant factor. This factor is the nature of the fruiting medium. In this context the question presents itself as to the extent to which observations carried out on sand and water cultures can be compared with those carried out on cultures grown under normal soil conditions. In nutrient solutions the ions can move freely, whereas those in the soil are adsorbed on colloidal particles or fixed in crystals. (JENNY and Cowan, 1953). The last-named investigators found that, in the presence of a small quantity of calcium, soybean plants exhibited higher yields in a system in which this calcium could move freely than in a system in which the same quantity of calcium was adsorbed on colloids. On the other hand, when greater quantities of calcium were present, the plants grew better in the adsorbed system.

Analogous to this example, the results achieved by BrapY et al. (1948) and other investigators with quartz sand (the free system) differ from those of the 1952 and 1953 experiments with soil and dusarit (the adsorbed system). Whereas BRADY et al. (1948) achieved good fructification with small quantities af calcium, which were added to the quartz sand either separately or in combination with potassium, the favourable influence of calcium in the 1953 experiments only found expression when calcium was present in great quantities in the fruiting medium. For, in the 1953 test, it was found that if $\mathrm{K}$ or $\mathrm{Mg}$ was administered in excess the assimilation of calcium was suppressed as a result of the antrgonism of $\mathrm{K}$ or Mg to Ca. Brady et al. (1948), on the other hand, found that potassium had no detrimental effect on fructification if it was applied in excess quantity with reference to calcium; in this connection the $\mathrm{Ca}$ and $\mathrm{K}$ quantities were 80 p.p.m. and 320 or 380 p.p.m., 20 p.p.m. and 160 or 320 p.p.m., respectively. Strauss and Grizzaro (1948) found that the average weight of shell per plant increases as the quantity of $\mathrm{Ca}$ in the adsorption complex increases. MeHuich and ReEd (1947) arrived at a similar conclusion, viz., that, to produce the same total quantity of shell, soils containing the clay mineral montmorillonite have to possess more calcium than soils containing kaolinite.

From this it appears that differences in the physiochemical properties of the fruiting zone also produce differences in results.

A primary factor, which must necessarily be present in the fruiting medium to enable assimilation of nutritive elements by the gynophores, is water, as was shown in the 1951 experiment.

Of the nutritive elements calcium is indispensable; if fructification is to start calcium has to be available to the gynophores in the fruiting medium to a sufficient extent, inter alia with regard to other ions present. As BLEDSOE et al. (1949) put it, the calcium is inadequately transported in the plant. In this connection, the investigators mentioned stress the relative immobility of calcium in the plant, mentioned by Mason and PhiLLus (1937). As has already been said 
in the introduction, this inadequate transport was demonstrated by BLEDSOE et al. (1948) in an experiment with radioactive calcium. From an examination of the literature of the subject, WIERsum (1951) concluded that transport of calcium can only take place via the xylem, and transport of the other substances via the sieve tubes, according to the hypothesis of MüNCH (1930). WiERsum then showed that no transport of water to the fruit takes place unless the fruit or gynophores is exposed to the air.

The period during which calcium is made available for the gynophores is important. Brady (1948) showed that calcium has the greatest effect on fructification if it is supplied to the soil between 15 and 35 days after the gynophores have penetrated into the soil. If it is supplied after this period, only slight fructification will result. This period of calcium requirement is in conformity with the hypothesis of Colwell and Brady (1945), which attributes to calcium, apart from its other functions, the quality of reducing the number of abortions of ovules - a hypothesis based on the connection between the increase in the percentage of two-kernel shells by calcium manuring in the fruit development zone and the fact that the ovary almost always contains two, and sometimes three, ovules.

CoLwell et al. (1945) performed chemical analyses of fruits which they obtained from manurial trials. The shells of the seeds analyzed had a low calcium content and high nitrogen, magnesium and potassium contents, which were hardly affected by calcium manuring. An increase in the quantity of calcium in the shells was found, however, in the gynophores manured with calcium, and this prompted the investigators to presume that a high calcium concentration in the shell is responsible, via a mechanism which is still unknown, for good pod-filling.

It will not be superfluous also to consider here the function of calcium as a factor in the transport of carbohydrates. In observations relating to this (Millen, 1938), plants deficient in Ca exhibited breakdowns in the transport of carbohydrates. It is not known whether the calcium taken up by the roots also performs this function.

The effect of potassium manifested itself in two aspects in the investigation, viz., as unfavourable to fructification when it was present alone or combined in an excess quantity with calcium, and favourable to fructification when $\mathrm{Ca}$ occurred in excess quantity. The potassium content in the root zone would appear to be of importance here. According to Rocers (1948), the peanut is a plant that can tolerate a high $\mathrm{Ca} / \mathrm{K}$ ratio and is capable of absorbing luxury quantities of $\mathrm{K}$ which are far in excess of what it needs for normal growth.

BURKHART and Coliss (1942) found in field trials that potassium manuring of soil with a low $\mathrm{Ca}$ content and moderate $\mathrm{K}$ content reduces the quantity of good pods. Likewise from a field trial, Brady and Colwell (1945) conclude that potassium manuring will result in an increase in yield provided the soil contains sufficient calcium and is very poor in potassium. In the 1953 experiment no analysis was made of the soil in which the plants themselves grew, and the possibility therefore exists, in connection with the deficiency symptoms which manifested themselves, that the potassium content of the plants was low. BLEDSOE and HARRIS (1950) achieved no reduction in fructification when potas- 
sium was withheld from the rooting medium and a full nutrient solution was administered to the fruiting medium.

In the 1953 experiment magnesium, like potassium, was found to be antagonistic to calcium, but had a less harmful effect on the gynophores than potassium. Brady et al. (1948) attribute a favourable influence to magnesium. The result obtained by them with quartz sand to which magnesium had been added in the form of $\mathrm{MgSO}_{4}$ was characterized, by comparison with distilled water, by an improvement in quality and an increase in the percentage of podfilling. On the other hand, Brady and Colwell (1945) concluded from their trials that $\mathrm{Mg}$ manuring generally affects seed development unfavourably.

The symptoms observable on the gynophores in the 1953 experiment, caused by the toxic effect of potassium and magnesium, can be best be explained by reference to the investigations carried out by TRUE and his associates (MILLER, 1938) regarding the function of calcium as a constituent of the middle lamella of the cell wall. True et al. found that roots ir a solution of a sodium or potassium salt were not capable of continuing absorption, but ultimately imparted more ions to the growth medium than they had ever been able to assimilate. In solutions of calcium and magnesium a concentration was found beneath which the roots were not capable of absorbing; on the other hand, in the case of solutions above this concentration, absorption took place to a greater or lesser extent.

Millen (1938) presumes that, in a solution of mixed salts, calcium somehow creates conditions which render possible the absorption of ions that are not observed when calcium is absent, or which cause a removal of these ions from the plant. The behaviour of these diffusion relations can be explained - albeit only in part - by the following microchemical observations.

It was found that plants which grew in $\mathrm{K}$ solutions quickly diffused ions from the middle lamellae. Instead of $\mathrm{Ca}$ pectate $\mathrm{K}$ pectate was formed, and the latter speedily dissolved, since $K$ pectate is soluble in water. At this stage salts and organic substances began to wash out the cell vacuoles. In solutions of $\mathrm{Mg}$ salts the $\mathrm{Ca}$ pectate was replaced by $\mathrm{Mg}$ pectate, which is insoluble but more permeable than $\mathrm{Ca}$ pectate. The detrimental results of this were not noticeable until the calcium had been entirely replaced by magnesium, after which sufficient $\mathrm{Mg}$ ions were present to penetrate the protoplasm and dainage it.

True assumed that the integrity of the $\mathrm{Ca}$ pectate will be maintained if sufficient $\mathrm{Ca}$ ions are present in the external medium. When the concentration of calcium falls below equilibrium, other cations will replace the calcium.

If the results of the peanut experiments in 1952 and 1953 are reviewed again - more particularly the results from the treatments containing potassium or magnesium, in which potassium caused rotting but magnesium exhibited a certain measure of intactness side by side with rotting - a high degree of conformity will be found with the observations of True.

It is not possible to say to what extent the $\mathrm{pH}$ 's influenced fructification in the 1953 experiment, because the quantities of $\mathrm{Ca}, \mathrm{K}$, and magnesium were not kept constant, and therefore, besides a varying $\mathrm{pH}$, a varying quantity of cations was also achieved. It may certainly be presumed that the gynophores can fructificate within a broad $\mathrm{pH}$ range, as can be seen from a field trial 
carried out by Brady and Colwell (1945) on a soil with a $\mathrm{pH}=\mathbf{4} .9$, and from the result of the 1953 experiment with a medium with $\mathrm{pH}=8.4$.

In this survey of results it is interesting to observe a feature of the situation which is also remarked upon by BLEDSOE and HARRIS (1950) and by Brady et al. (1948), viz., that it is highly probable that other factors besides that of the calcium available in the fruiting medium influence fructification. Under even the best nutritive conditions, the number of well-developed pods represents only a small percentage of the gynophores which penetrate the fruiting medium. It is not known whether the cause of this also lies in the organic part of the food. An indication in this direction is given by BRADY (1948), who presumes that competition must exist between the carbohydrates.

\section{BIBLIOGRAPHY}

Bledsoe, R. W., C. L. Comar and H. C. Hakris : Absorption of radioactive calcium by the peanut fruit. Science 109 (1949), 329-330.

-- , H. C. Harris and W. B. Tisdale: Leafspot of peanut associated with magnesium deficiency. Plant Physiology 21 (1946), 237-240.

- - , - : The influence of mineral deficiency on vegetative growth, flower and fruit production, and mineral composition of the peanut plant. Plant Physiology 25 (1950), 63-67.

BRADY, N. C. : The effect of calcium supply and mobility of calcium in the plant on peanut fruit filling. Soil Sc. Soc. of America, Proceedings 1947/1948, 336-341.

- - and W. E. Colwell : Yield and quality of largeseeded type peanuts as affected by potassium and certain combinations of potassium, magnesium and calcium. Journ. Amer. Soc. Agron. 37 (1945), 429-442.

- -, J. F. Reens and W. E. Colwell : The effect of certain elements on peanut fruit filling. Journ. Amer. Soc. Agron. 40 (1948), 155-167.

Burkhart, L. and E. R. Collins : Mineral nutrients in peanut plant growth. Soil Sc. Soc. of America, Proceedings 6, 1942, 272-280.

Colwell, W. E. and N. C. Brady: The effect of calcium on certain characteristics of peanut fruit. Journ. Amer. Soc. Agron. 37 (1945), 696-708.

- -, - -, J. R. Piland : Composition of peanut shells of filled and unfilled fruits as affected by fertilizer treatments. Journ. Amer. Soc. Agron. 37 (1945), 792-805.

HARris, H. C.: The effect on the growth of peanuts of nutrient deficiencies in the root and pegging zone. Plant Physiology 24 (1949), 150-161.

JAcoBs, W. P.: The development of the gynophore of the peanut plant, Arachis hypogaea L., I. Amer. Journ. Bot. 34 (1947), 361-370.

JENNY, H. and E. W. CowAN: The utilisation of absorbed ions by plants. Science 77 (1933), 394-396.

LEHR, J. J. : Exploratory pot experiments on sensitiveness of different crops to sodium : B. Oats. Plant and Soil 4 (1953), 289-297.

Mason, T. G. and E. Prrulrs : The migration of solutes. Bot. Rev. 3 (1937), 47-71.

Mertich, A. and J. F. REED: The influence of type of colloid and degree of calcium saturation on fruit characteristics of peanuts. Soil Sci. Soc. of America, Proceedings 11, 1947, 201-205.

Mruler, E. C. : Plant Physiology. New York, 1938.

Münch, E. : Die Stoffbewegungen in der Pflanze. Jena, 1930.

REED, E. L. : Anatomy, embryology and ecology of Arachis hypogaea L. Botanical Gaz. 78 (1942), 289-310.

RoGErs, H. T. : Liming for peanuts in relation to exchangeable soil calcium and effect on yield, quality and uptake of calcium and potassium. Journ. Amer. Soc. Agron. 40 (1948), 15-31.

ShibuYA, T.: Morphological and physiological studies in the fructification of peanut. Mem. Fac. Sci. and Agr., Taihoku Imp. Univ., 17 (1935), 1-120.

Sommer, Anna L. and A. Baxter: Differences in growth limitations of certain plants by magnesium and minor element deficiencies. Plant Physiology 17 (1942), 109-116. 
S'rokes, W. E. and F. H. Hull: Peanut breeding. Journ. Amer. Soc. Agron. 22 (1930), $1004-1019$.

Strauss, J. L. and A. L. Gruzzard : The effect of calcium, magnesium and potassium on peanut yields. Soil Sci. Soc. of America, Proceedings 1947, 12 (1948), 348-352.

Thornton, G. D. and F. E. Broadbent : Preliminary greenhouse studies of the influence of nitrogen fertilization of peanuts on nodulation, yield and gynophore absorption of this element. Journ. Amer. Soc. Agron. 40 (1948), 64-69.

Wiersum, L. K. : Watertransport in the xylemas related to calcium uptake by groundnuts (Arachis hypogaea L.). Plant and Soil 3 (1951), 160-169.

WolK, P. C. VAN DER: Researches concerning geocarpy. Publications sur la physiologie végétale. Nimègue, 1914.

Erratum to

\title{
INFLUENCE OF TILTH ON SOIL AND AIR-TEMPERATURE
}

\author{
R. H. A. VAN DUIN \\ Laboratory for Physics and Meteorology, Agrilcultural University, \\ The Netherlands
}

In the arcticle mentioned in the title (Neth. J. Agr. Sci. 2, 1954, 4 : 229-241) the phase shift between the heatflux into a layered soil and the temperature wave at the surface must read:

$$
-\varphi=\operatorname{arctg} \frac{\frac{Q_{s}}{Q_{a}} \sin \left(\frac{\pi}{4}-\Delta \varphi_{0}\right)+\sin (\operatorname{arctg} 1 / 2 j)}{\frac{Q_{s}}{Q_{G}} \cos \left(\frac{\pi}{4}-\Delta \varphi_{0}\right)+\cos (\operatorname{arctg} 1 / 2 j)}
$$

where $Q_{s} Q_{a}$ is given by eq. $13 a$.

The results of the calculations in the case of a dry soil with $q_{\mathrm{s}}+q_{\mathrm{a}}=$ constant are decreased by about $3 \%$ if eq. $17 \mathrm{a}$ is used. Owing to this correction the corresponding part of table 3 must be replaced by:

\begin{tabular}{|c|c|c|c|c|c|c|c|c|}
\hline & \multicolumn{4}{|c|}{$\mathrm{z}=0$} & \multicolumn{4}{|c|}{$\mathrm{z}=+5 \mathrm{~cm}$} \\
\hline & $\mathrm{I}_{i}$ & $I_{d}$ & II $=$ & $\mathrm{II}_{\mathrm{d}}$ & I & $I_{d}$ & $\mathrm{II}_{\mathrm{c}}$ & $\mathrm{II}_{\mathrm{d}}$ \\
\hline$\underset{T_{\min }}{A}$ & $\begin{array}{r}18.3 \\
-4.3\end{array}$ & $\begin{array}{r}21.6 \\
-7.6\end{array}$ & $\begin{array}{r}27.8 \\
(-13.8)\end{array}$ & $\begin{array}{r}32.8 \\
(-18.8)\end{array}$ & $\begin{array}{r}14.6 \\
-0.6\end{array}$ & $\begin{array}{c}17.3 \\
(-3.3)\end{array}$ & $\begin{array}{c}22.2 \\
(-8.2)\end{array}$ & $\begin{array}{r}26.2 \\
(-12.2)\end{array}$ \\
\hline
\end{tabular}

